\title{
Electrical Properties Of Polymer Nano-composites Based On Oxide And Nitride Fillers
}

\author{
I. L. Hosier, M. Praeger, A. S. Vaughan and S. G. Swingler \\ Tony Davis High Voltage Laboratory \\ University of Southampton \\ Southampton, SO17 1BJ, UK \\ ILH@ecs.soton.ac.uk
}

\begin{abstract}
Four polyethylene based nano-composites containing either silica or silicon nitride were prepared. After verifying their compositions and morphologies, their dielectric properties were followed as a function of conditioning (absorbed water content). The dielectric loss and DC breakdown strength were found to be strongly dependent on conditioning whilst the properties of a control sample (with no nano-filler) were found to be invariant. Under ambient conditions, silicon nitride provides a composite with reduced dielectric loss and increased breakdown strength compared to an analogous system employing silica. Silicon nitride based systems exhibit improved breakdown strength relative to the host polymer when dried and therefore hold significant potential for use in future HVDC cables.
\end{abstract}

Keywords-Nano-composites; dielectric loss; DC breakdown strength; water absorption

\section{INTRODUCTION}

With the drive towards the use of renewable energy sources comes the need for improved high voltage cable systems, particularly for long distance HVDC operation. Traditionally a polymeric insulated cable is used and these have the advantages of low cost, high breakdown strength and low dielectric losses. Nano-composites (where a nano-scale filler is incorporated into a polymeric host matrix) have significant potential to offer improvements in breakdown strength and hence are an attractive way towards improved dielectrics for the next generation of HVDC cables. Despite this, the majority of reports in the literature focus on their advantageous mechanical and thermal properties and not on their electrical properties. In terms of systems employing nano-silica, the situation regarding electrical properties is far from clear since achieving good particle dispersion is very difficult [1-5] and the measured dielectric properties are very sensitive to absorbed water [4-7]. This remains a fundamental barrier to the commercial exploitation of such composites and therefore urgent work is needed to understand and mitigate these effects.

On the other hand, a silicon nitride based system could provide potential advantages over an oxide based system through a reduction of surface hydroxyl groups [4], leading potentially to a composite with dielectric properties that are much less influenced by absorbed water. Furthermore, their improved thermal conductivity could provide cables capable of increased power rating for the same geometry, resulting in potential cost savings despite the higher cost of the filler.
Despite this, only one study of their electrical properties exists to our knowledge [8] and this shows a useful increase in AC and DC breakdown strength is possible in such composites.

In this paper we have used a new method of solvent blending aimed at improving particle dispersion. After characterising the resulting silica and silicon nitride based composites, their dielectric properties were then followed as a function of conditioning (i.e. absorbed water content). We have contrasted the behaviour of the two types of composites.

\section{EXPERIMENTAL}

\section{A. Sample Preparation and Conditioning}

Silicon nitride $\left(\mathrm{Si}_{3} \mathrm{~N}_{4}\right)$ and silica $\left(\mathrm{SiO}_{2}\right)$ nano-powders were obtained from Sigma Aldrich (items 636703 and 637238). The polymer host material was a melt blended batch of $20 \%$ HDPE (BP Rigidex HD5813EA) and $80 \%$ LDPE (ExxonMobil LD100BW) [3-5]. The required amount of nano-filler $(0.25 \mathrm{~g}$ or $0.5 \mathrm{~g}$ ) was dispersed in $10 \mathrm{ml}$ of isopropyl alcohol; this was sonicated for 10 minutes using a Hielscher UP200S probe sonicator stirring the mixture halfway through. In the meantime, $5 \mathrm{~g}$ of the host polymer was dissolved in $50 \mathrm{ml}$ xylene by gently boiling the mixture. The solution was then removed from the heat and the nano-filler/IPA solution was immediately added under constant stirring. Stirring was maintained until the material had formed a waxy solid, at which point it was left in a drying cabinet vented to outside for 3 days, followed by vacuum drying for a further $24 \mathrm{~h}$. Samples for analysis were prepared using a heated laboratory hydraulic press at $160^{\circ} \mathrm{C}$ and were crystallised in an oil bath at $115^{\circ} \mathrm{C}$ for $1 \mathrm{~h}$ [3-5]. Ambient conditioning was carried out by exposing samples to ambient conditions $\left(19 \pm 2{ }^{\circ} \mathrm{C}\right.$ and $\left.55-80 \% \mathrm{RH}\right)$ for two weeks. Dry conditioning was performed by vacuum drying at room temperature whilst wet conditioning was performed by immersion in distilled water. Both types of conditioning were carried out for a maximum of two weeks.

\section{B. Sample Characterisation}

The filler content of the blends was determined by heating small samples $(5 \mathrm{mg}$ ) in air on a Perkin Elmer Pyris 1 TGA to $700{ }^{\circ} \mathrm{C}$ at a rate of $20 \mathrm{~K} / \mathrm{min}$. Differential scanning calorimetry (DSC) was performed on a Perkin Elmer DSC-7 with a heating rate of $10 \mathrm{~K} / \mathrm{min}$ and a cooling rate of $5 \mathrm{~K} / \mathrm{min}$. Samples for scanning electron microscopy (SEM) were etched for $4 \mathrm{~h}$ using 
TABLE I. MATERIALS USED IN THESE INVESTIGATIONS

\begin{tabular}{|l|l|l|}
\hline \multicolumn{1}{|c|}{ Designation } & \multicolumn{1}{|c|}{ Filler type/content } & $\begin{array}{c}\text { Measured residue from } \\
\text { TGA (\%) }\end{array}$ \\
\hline Control & - & $<0.1$ \\
\hline SiN05 & $5 \%$ Silicon nitride & $4.5 \pm 0.2$ \\
\hline SiN10 & $10 \%$ Silicon nitride & $8.3 \pm 0.3$ \\
\hline SiO05 & $5 \%$ Silica & $4.2 \pm 0.1$ \\
\hline SiO10 & $10 \%$ Silica & $8.5 \pm 0.2$ \\
\hline
\end{tabular}

a standard permanganic reagent [2-5], mounted onto standard aluminium SEM stubs, gold coated and then examined at 15 $\mathrm{kV}$ in a Jeol JSM6500F high resolution FEGSEM.

Dielectric spectroscopy was performed on $0.2 \mathrm{~mm}$ thickness samples incorporating gold coated $30 \mathrm{~mm}$ diameter electrodes. Measurements were performed from $0.1 \mathrm{~Hz}$ to 1 MHz using a Solartron 1296 dielectric interface linked to a Schlumberger SI 1260 impedance-gain-phase analyzer. DC breakdown testing was carried out on $0.1 \mathrm{~mm}$ thickness samples placed between opposing $6.3 \mathrm{~mm}$ chrome steel ball bearings immersed in silicone fluid (Dow Corning 200/20CS). An increasing DC voltage $(100 \mathrm{~V} / \mathrm{s})$ was applied to this arrangement until failure occurred. For each composite system, 20 such tests were carried out in separate locations and the data were then analysed using Weibull statistics.

\section{RESULTS}

\section{A. Physical Characterisation}

Table I provides a list of the samples used in these investigations. The TGA results, (also shown in Table I) indicate a residue (filler) somewhat less than expectations indicating that some filler is lost during the preparation process or equally that some water is present in the starting powders. The DSC results (Fig. 1) show two peaks on heating, one associated with the LDPE $\left(105^{\circ} \mathrm{C}\right)$ and the second associated with the HDPE $\left(124{ }^{\circ} \mathrm{C}\right)$; the melting behaviour is clearly

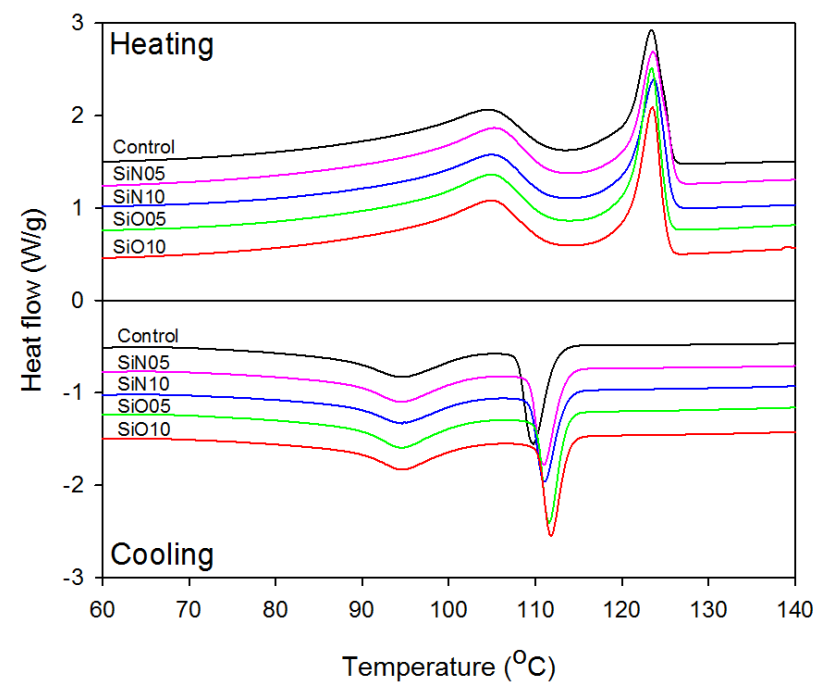

Fig. 1. DSC melting and crystallisation traces (curves displaced for clarity). unaffected by the presence of the nano-filler. On cooling, the crystallisation of the LDPE is unaffected by the nano-filler and occurs at $95{ }^{\circ} \mathrm{C}$. However, the crystallisation of the HDPE $\left(110{ }^{\circ} \mathrm{C}\right.$ in the control) occurs significantly earlier in the presence of silica $\left(112{ }^{\circ} \mathrm{C}\right)$ and somewhat earlier in the presence of the nitride $\left(111^{\circ} \mathrm{C}\right)$ indicating that they are having a nucleating effect $[4,5]$. Furthermore the total enthalpy is reduced from $112 \mathrm{~J} / \mathrm{g}$ to $106 \mathrm{~J} / \mathrm{g}$ and $100 \mathrm{~J} / \mathrm{g}$ respectively in 5 and $10 \%$ blends which is in line with expectations.

SEM micrographs are shown in Figs. 2 and 3. Whilst the control sample contained banded spherulites as expected [3-5] both nitride composites show a good dispersion of the filler within the host polymer (Fig. 2). The individual particles are $<1 \mu \mathrm{m}$ in size (which is in line with the expected dimensionality) but a few aggregates up to $2 \mu \mathrm{m}$ in size were nevertheless noted. Fig. 3 shows analogous images of the silica composites. As well as a high proportion of the expected $<1 \mu \mathrm{m}$ sized particles, indicating improved dispersion over the previous silica composites $[4,5]$, there remain some large aggregates up to $10 \mu \mathrm{m}$ in size. Examination of the silica powder as supplied confirms that similar aggregates are present. It is unclear at present whether changing the sonication conditions would be effective at breaking these up but this is certainly an area that is worthy of future exploration.
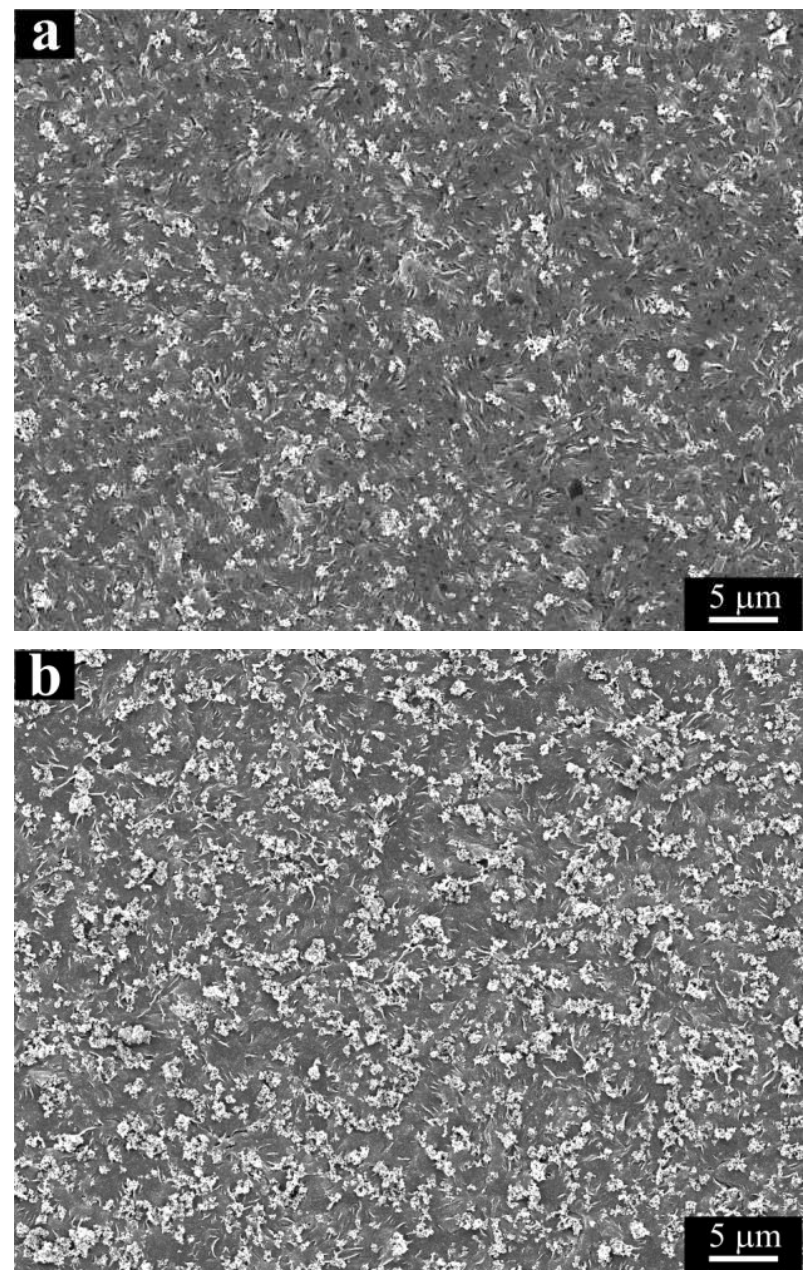

Fig. 2. SEM micrographs of (a) SiN05 and (b) SiN10. 

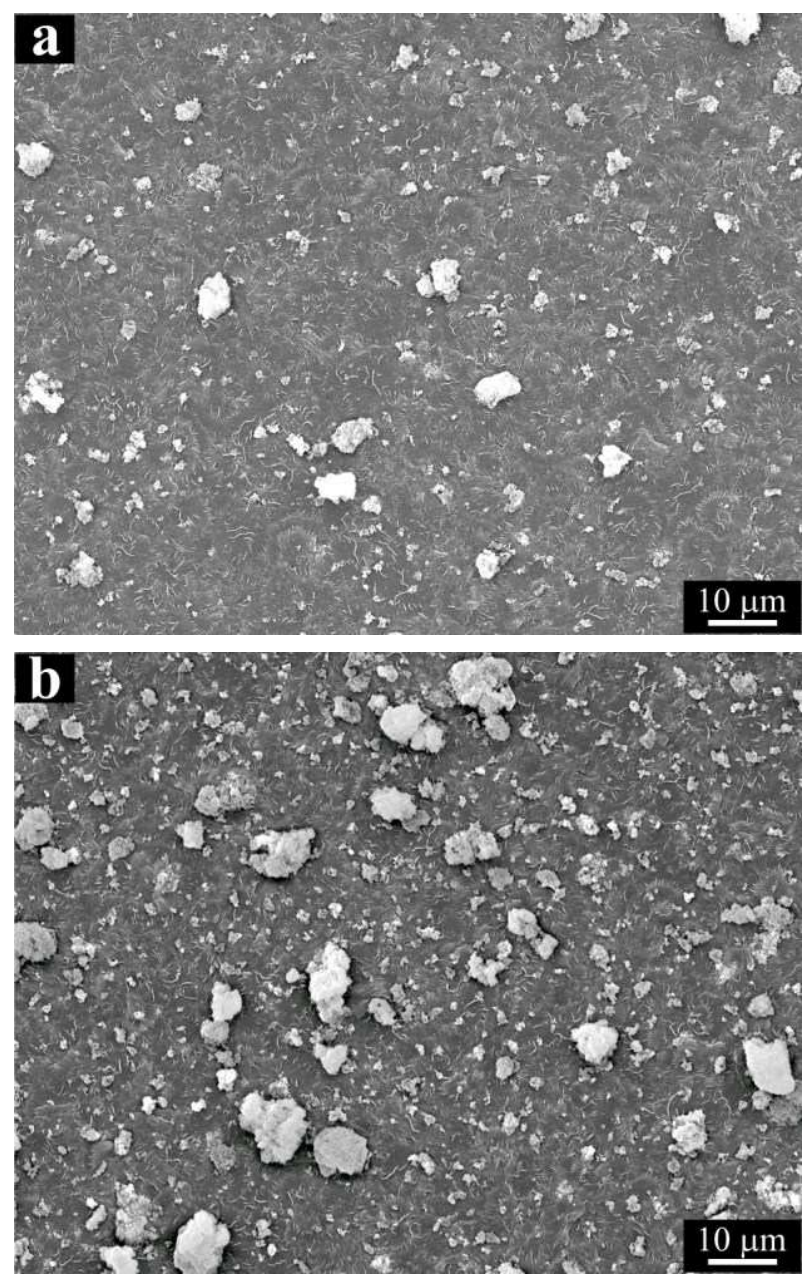

Fig. 3. SEM micrographs of (a) SiO05 and (b) SiO10.

\section{B. Electrical Properties}

Measurements of mass change as a function of conditioning time are shown in Fig. 4 for both dry and wet conditioning

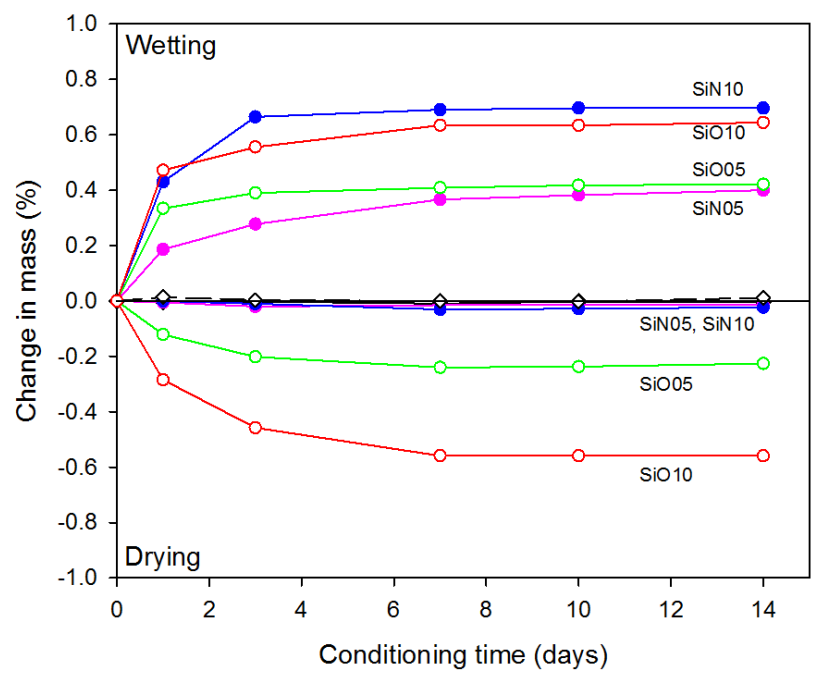

Fig. 4. Effect of conditioning on measured water content. using ambient conditions as a reference; all samples reach a steady state after $\sim 7$ days of conditioning. The control sample shows negligible water absorption or loss, whilst the silicon
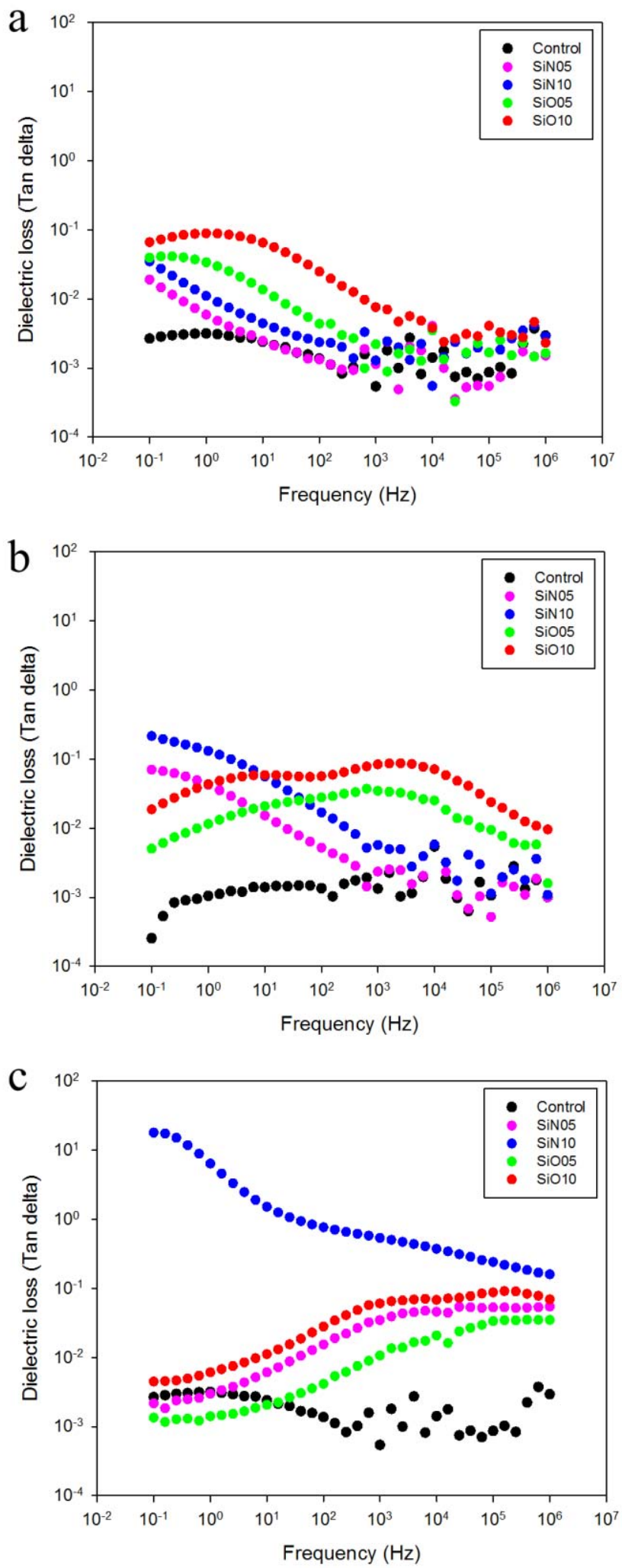

Fig. 5. Dielectric loss following (a) dry (14 d), (b) ambient and (c) wet (14 d) conditioning. 
nitride composites do not lose much water when dried $(<$ $0.03 \%$ ) but are capable of absorbing significant water (up to $0.7 \%$ ) when wet conditioned. In contrast the silica composites can lose up to $0.5 \%$ or gain up to $0.7 \%$ of water; values that are in line with previous investigations $[4,5]$. This behaviour indicates that the silicon nitride composites stored under ambient conditions are largely free of absorbed water whereas the water content of the silica composites is substantial.

Selected measurements of dielectric loss are shown in Fig. 5 which demonstrate that the control sample always displays a low dielectric loss $\left(<10^{-2}\right)$ regardless of conditioning. In both silica composites a double relaxation feature in the mid frequency range is apparent, which moves to higher frequencies with increasing water content indicative of increased ion mobility [4-7]. In contrast, the nitrides show a low frequency loss feature (Fig. 5b), perhaps arising due to Maxwell-Wagner polarisation [1], but this can be largely eliminated through drying (Fig. 5a). Wet conditioning (Fig. 5c) of SiN05 results in similar spectra to SiO10 indicating similar charge transport. In contrast, $\mathrm{SiN} 10$ shows a very high loss and a switch from capacitive to resistive behaviour at low frequencies which suggests the formation of a percolating water network. It is clear from this that oxide and nitride fillers lead to fundamentally different modes of behaviour.

An example of a Weibull plot from DC breakdown is shown in Fig. 6 and numerical data are shown in Table II. Under ambient conditioning, both nitride composites have a breakdown strength only slightly reduced from that of the control $(\sim 420 \mathrm{kV} / \mathrm{mm})$ whilst the silica nano-composites display a much lower breakdown strength. Following drying (Table II), the breakdown strength is improved such that all four composites now have values that are close to or, in the case of SiN10, exceed that of the host polymer. Whilst this is an exciting result, there is clearly room for further improvement through functionalization [8]. These findings should be contrasted to our previous work $[2,3,5]$ where the breakdown strength of the (less well dispersed) silica composite was always less than the host polymer even when dried. Wet conditioning always has a detrimental effect.

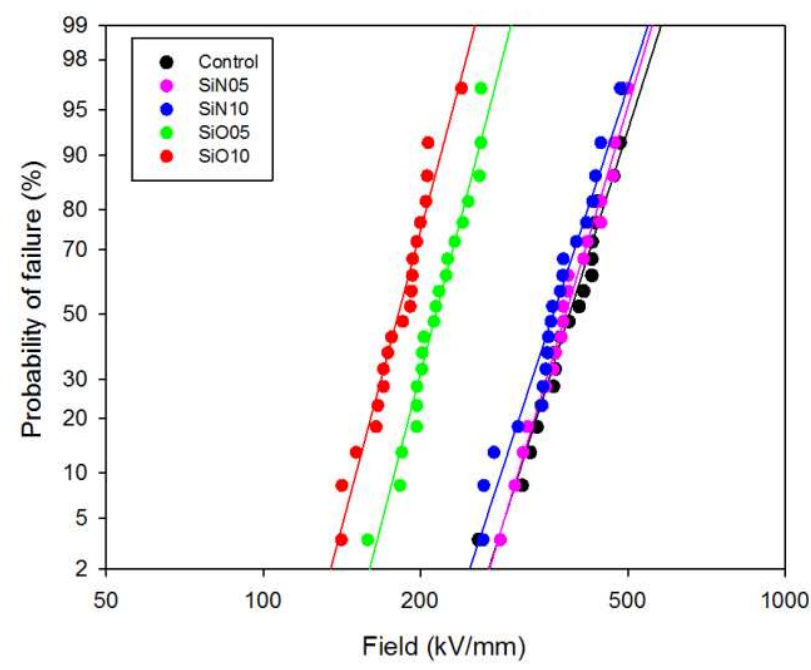

Fig. 6. Weibull plot obained from ambient conditioned composites.
TABLE II. RESULTS OF DC BREAKDOWN TESTING

\begin{tabular}{|c|c|c|c|}
\hline \multirow{2}{*}{ Composite } & \multicolumn{3}{|c|}{ Weibull results - kV/mm ( $\beta)$} \\
\hline & Dry (14 d) & Ambient & Wet (14 d) \\
\hline Control & $425 \pm 15(8.0)$ & $416 \pm 15(7.7)$ & $408 \pm 16(6.8)$ \\
\hline SiN05 & $431 \pm 17(6.7)$ & $409 \pm 15(7.1)$ & $172 \pm 7(6.0)$ \\
\hline SiN10 & $450 \pm 13(8.5)$ & $389 \pm 14(7.0)$ & $150 \pm 6(6.2)$ \\
\hline $\mathrm{SiO} 05$ & $431 \pm 15(6.7)$ & $228 \pm 7(8.6)$ & $135 \pm 6(5.2)$ \\
\hline $\mathrm{SiO} 10$ & $414 \pm 15(7.3)$ & $194 \pm 6(8.1)$ & $102 \pm 3(11.0)$ \\
\hline
\end{tabular}

IV. CONCLUSIONS

Four nano-composites were prepared using a new solvent based technique. Conditioning experiments showed that the dielectric loss and DC breakdown strength of the nanocomposites is highly dependent on absorbed water content. Under ambient conditions silicon nitride offered improved properties over silica by virtue of lower water content. Drying could substantially improve the dielectric properties of the composites, such that a composite containing $10 \%$ silicon nitride displayed a useful increase in DC breakdown strength over the host polymer. With proper treatment, silicon nitride nano-composites have significant potential to provide enhanced materials for HVDC cable applications.

\section{ACKNOWLEDGMENT}

The authors gratefully acknowledge the RCUK's Energy Programme for the financial support of this work through the Top \& Tail Transformation programme grant, EP/I031707/1 (http://www.topandtail.org.uk/).

\section{REFERENCES}

[1] S. L. Abd-El Messieh, N. N. Rozik, "Dielectric and morphological studies on polyester/nanosilica fume composites", J. Appl. Polym. Sci., Vol. 122, pp. 714-721, 2011.

[2] M. Praeger, A. S. Vaughan, S. G. Swingler, "The breakdown strength and localized structure of polystyrene as a function of nanosilica fill fraction", In Proc. 2013 Int. Conf. Sol. Diel, IEEE, pp. 863-866, 2013.

[3] K. Y. Lau, A. S. Vaughan, G. Chen, I. L. Hosier, A. F. Holt, K. Y. Ching, "On the space charge and DC breakdown behavior of polyethylene/silica nanocomposites", IEEE Trans. Diel. Electr. Insul., Vol. 21, pp 340-351, 2014.

[4] K. Y. Lau, A. S. Vaughan, G. Chen, I. L. Hosier, "On the dielectric response of silica based polyethylene nanocomposites", J. Phys. D: Appl. Phys, Vol. 46, Art. No. 095303, 2013.

[5] I. L. Hosier, M. Praeger, A. F. Holt, A. S. Vaughan, SG Swingler, "Effect of water absorption on dielectric properties of nanosilica/polyethylene composites", In Proc. 2014 IEEE Conf. Electr. Insul. Diel. Phen., pp.651-654, 2014.

[6] A. Sami, M. F. Frechette, Eric David and S. Savoie, "Water as a Digression Relative to the Dielectric Response in the Frequency Domain for Polymer Composites", In 2008 Ann Rep Conf Electr. Insul Diel Phen, pp. 501-504, 2008

[7] L. Hui, L. S. Schadler, J. K. Nelson, "The Influence of Moisture on the Electrical Properties ofCrosslinkedPolyethylene/SilicaNanocomposites", IEEE Trans. Diel. Electr. Insul., Vol. 20, pp. 641-653, 2013.

[8] G. C. Xu, J. Wang, X. L. Ji, J. Y. Xiong and F. Li, "Effect of Nanosilicon Nitride on the Mechanical and Electric Properties of Polypropylene Nanocomposite", J. Comp. Mat., Vol. 41, 2007, pp.2213 2223., 2007. 